$7-2009$

\title{
A New Control Method for Input-Output Harmonic Elimination of the Pwm Boost-Type Rectifier Under Extreme Unbalanced Operating Conditions
}

\author{
Ana Vladan Stankovic \\ Cleveland State University, a.stankovic@csuohio.edu \\ Kel|Ghehis and additional works at: https://engagedscholarship.csuohio.edu/enece_facpub \\ '’rveland State University, kevin.chen@kema.com \\ Part of the Controls and Control Theory Commons, and the Electronic Devices and Semiconductor \\ Manufacturing Commons
}

How does access to this work benefit you? Let us know!

\section{Publisher's Statement}

(C) 2009 IEEE. Personal use of this material is permitted. Permission from IEEE must be obtained for all other users, including reprinting/ republishing this material for advertising or promotional purposes, creating new collective works for resale or redistribution to servers or lists, or reuse of any copyrighted components of this work in other works.

\section{Original Citation}

Stankovic, A. V., \& Ke, C. (2009). A new control method for input-output harmonic elimination of the PWM boost-type rectifier under extreme unbalanced operating conditions. IEEE Transactions on Industrial Electronics, 56, 7, 2420-2430.

\section{Repository Citation}

Stankovic, Ana Vladan and Chen, Ke, "A New Control Method for Input-Output Harmonic Elimination of the Pwm Boost-Type Rectifier Under Extreme Unbalanced Operating Conditions" (2009). Electrical Engineering \& Computer Science Faculty Publications. 111.

https://engagedscholarship.csuohio.edu/enece_facpub/111

This Article is brought to you for free and open access by the Electrical Engineering \& Computer Science Department at EngagedScholarship@CSU. It has been accepted for inclusion in Electrical Engineering \& Computer Science Faculty Publications by an authorized administrator of EngagedScholarship@CSU. For more information, please contact library.es@csuohio.edu. 


\title{
A New Control Method for Input-Output Harmonic Elimination of the PWM Boost-Type Rectifier Under Extreme Unbalanced Operating Conditions
}

\author{
Ana Vladan Stankovic, Member, IEEE, and Ke Chen
}

\begin{abstract}
Under severe fault conditions in the distribution system, not only input voltages but also input impedances must be considered as unbalanced. This paper presents a new control method for input-output harmonic elimination of the pulsewidthmodulation (PWM) boost-type rectifier under conditions of both unbalanced input voltages and unbalanced input impedances. The range of imbalance in both input voltages and input impedances, for which the proposed method is valid, is analyzed in detail. An analytical approach for complete harmonic elimination shows that PWM boost-type rectifier can operate at unity power factor under extremely unbalanced operating conditions resulting in a smooth (constant) power flow from ac to de side. Based on the analyses in open-loop configuration, a feedforward control method is proposed. Elimination of harmonics at ac and de side of the converter affects the cost of de link capacitor and ac side filter. The proposed method is very useful when the PWM boost-type rectifier is subject to extreme imbalance due to severe fault conditions in the power system. In addition, by using the proposed method, the PWM boost-type rectifier can be operated from the single-phase supply in cases where three-phase source is not available. Simulation results show excellent response and stable operation of the PWM boost-type rectifier under the proposed control algorithm. Experimental and simulation results are in excellent agreement.
\end{abstract}

Index Terms-Harmonic elimination, pulsewidth-modulation (PWM) boost-type rectifier, unbalanced input voltages and impedances, unity power factor.

\section{INTRODUCTION}

$\mathbf{T}$ HE PULSEWIDTH-MODULATION (PWM) boost-type rectifier has been increasingly employed in recent years [3], [7]. It offers advantages over traditionally used phasecontrolled rectifiers in ac/dc/ac converters for variable control drives because of its capability for nearly instantaneous reversal of power flow, power factor management, and reduction of input harmonic distortion. Although numerous papers have been written about the PWM boost-type rectifier, its operation under unbalanced input supply voltages and impedances has not been analyzed in detail. Such an imbalance may occur frequently, particularly in weak systems. Nonuniformly distributed single-phase loads, faults, or unsymmetrical transformer windings could cause imbalance in the three-phase supply both in magnitude and in phase. Regardless of the cause, unbalanced input voltages have a severe impact on the performance of the PWM boost-type rectifier. An unbalanced input supply results in the appearance of large low-order harmonics at the rectifier output as well as low-order harmonics in the input currents that pollute the utility [2]. Such harmonic pollution has been of the growing concern in recent years. In addition to harmonic pollution at the ac side of the converter, the ripple at the $\mathrm{dc}$ link is a known cause of interaction between current regulators which could even cause system instability. The problem increases as the number of converters at the link increases. Attempts have been made to reduce harmonics at the input and the output of the PWM boost-type rectifier under unbalanced operating conditions [5]. However, harmonics were reduced but not eliminated. Enjeti and Choudhury [6] proposed a method of input harmonic elimination of the buck ac to dc converter. Stankovic and Lipo proposed a new control method for complete input-output harmonic elimination of the PWM boosttype rectifier under unbalanced operating conditions [1], [8], and [15]. However, this method suffers from two disadvantages: the power factor cannot be adjusted, and it cannot operate under extremely unbalanced operating conditions.

In [10], a new control method for a three-phase PWM boosttype rectifier based on output power control strategy was proposed. Even though the harmonics were completely eliminated, the input power factor cannot be controlled.

Recently, Suh et al. [9] and Suh and Lipo [11] proposed a control scheme in the synchronous stationary frame to improve the transient response of the PWM boost rectifier under unbalanced input conditions. A great deal of complexity is present in this approach.

Ojo and $\mathrm{Wu}$ [12] proposed a high-performance controller for harmonic elimination for a line side converter under unbalanced input voltages and impedances.

Even though the authors in [9], [11], and [12] considered the operation of the PWM boost-type rectifier under unbalanced input voltages and unbalanced input impedances, none of them considered the extreme simultaneous imbalance in both of them.

This paper proposes a completely new strategy in the abc reference frame for input output harmonic elimination of the PWM boost-type rectifier under extreme simultaneous imbalance in the input voltages and impedances. The proposed method is general and can be used for all levels of imbalance in input voltages and input impedances. The power factor can be adjusted in addition to the harmonic elimination. Based on the 


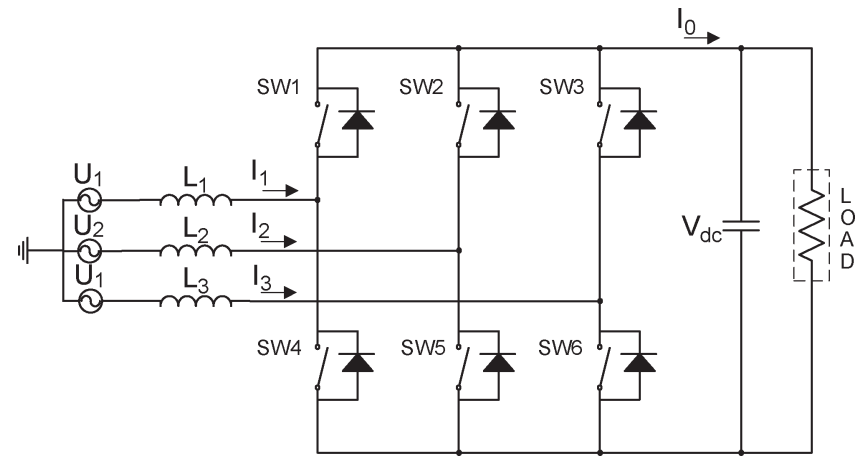

Fig. 1. PWM boost-type rectifier under unbalanced input voltages and unbalanced input impedances.

measurements of the input voltage and impedance unbalance, both magnitudes as well as phase angles of three input currents are adjusted. In spite of the level of imbalance in input voltages and input impedances, high quality of input currents and output $\mathrm{dc}$ voltage are obtained. The important result that follows is the possibility of operation of the three-phase PWM boost-type rectifier from a single-phase supply with essentially no input and output harmonics.

Theoretical, simulation, and experimental results are in excellent agreement.

\section{THEORETICAL APPROACH}

The circuit in Fig. 1 is analyzed under the following assumptions.

1) The input voltages are unbalanced.

2) The input impedances are unbalanced.

3) The converter is lossless.

\section{A. Derivation}

$$
\begin{aligned}
& U_{1}=z_{1} I_{1}+V_{s 1} \\
& U_{2}=z_{2} I_{2}+V_{s 2} \\
& U_{3}=z_{3} I_{3}+V_{s 3} \\
& I_{1}=-I_{2}-I_{3} \\
& S^{*}=U_{1}^{*} I_{1}+U_{2}^{*} I_{2}+U_{3}^{*} I_{3} \\
& S W_{1} I_{1}+S W_{2} I_{2}+S W_{3} I_{3}=0
\end{aligned}
$$

where $U_{1}, U_{2}, U_{3}, I_{1}, I_{2}, I_{3}, z_{1}, z_{2}, z_{3}, V_{s 1}, V_{s 2}, V_{s 3}, S$, $S W_{1}, S W_{2}$, and $S W_{3}$ are input voltages, input currents, input impedances, synthesized voltages at the input of the rectifier, apparent power, and switching functions, respectively, represented as phasors.

Equation (6) represents the condition for the second harmonic elimination. Synthesized voltages $V_{s 1}, V_{s 2}$, and $V_{s 3}$ can be expressed as

$$
\begin{aligned}
& V_{s 1}=S W_{1} \frac{V_{\mathrm{dc}}}{2 \sqrt{2}} \\
& V_{s 2}=S W_{2} \frac{V_{\mathrm{dc}}}{2 \sqrt{2}} \\
& V_{s 3}=S W_{3} \frac{V_{\mathrm{dc}}}{2 \sqrt{2}}
\end{aligned}
$$

where $V_{\mathrm{dc}}$ is output dc voltage.
By substituting (7)-(9) into (1)-(3), the following set of equations is obtained:

$$
\begin{aligned}
& U_{1}=z_{1} I_{1}+S W_{1} \frac{V_{\mathrm{dc}}}{2 \sqrt{2}} \\
& U_{2}=z_{2} I_{2}+S W_{2} \frac{V_{\mathrm{dc}}}{2 \sqrt{2}} \\
& U_{3}=z_{3} I_{3}+S W_{3} \frac{V_{\mathrm{dc}}}{2 \sqrt{2}} \\
& I_{1}=-I_{2}-I_{3} \\
& S^{*}=U_{1}^{*} I_{1}+U_{2}^{*} I_{2}+U_{3}^{*} I_{3} \\
& S W_{1} I_{1}+S W_{2} I_{2}+S W_{3} I_{3}=0 .
\end{aligned}
$$

For given input power $S$; input voltages $U_{1}, U_{2}$, and $U_{3}$; input impedances $z_{1}, z_{2}$, and $z_{3}$; input currents $I_{1}, I_{2}$, and $I_{3}$ can be obtained from the above set of equations. By multiplying (10)-(12) by $I_{1}, I_{2}$, and $I_{3}$, respectively, and adding them up, the following equation is obtained:

$$
\begin{aligned}
U_{1} I_{1}+U_{2} I_{2}+ & U_{3} I_{3}=z_{1} I_{1}^{2}+z_{2} I_{2}^{2}+z_{3} I_{3}^{2} \\
& +\frac{V_{\mathrm{dc}}}{2 \sqrt{2}}\left(S W_{1} I_{1}+S W_{2} I_{2}+S W_{3} I_{3}\right) .
\end{aligned}
$$

By substituting (15) into (16), the following equation is obtained:

$$
U_{1} I_{1}+U_{2} I_{2}+U_{3} I_{3}=z_{1} I_{1}^{2}+z_{2} I_{2}^{2}+z_{3} I_{3}^{2} .
$$

The set of six equations with six unknowns, (10) to (15), reduces to three equations with three unknowns and are given by

$$
\begin{aligned}
& I_{1}=-I_{2}-I_{3} \\
& S^{*}=U_{1}^{*} I_{1}+U_{2}^{*} I_{2}+U_{3}^{*} I_{3} .
\end{aligned}
$$

Equations (17)-(19) represent a set of three equations with three unknowns. By substituting (18) into (17) and (19), the following set of equations is obtained:

$$
\begin{aligned}
& U_{1}\left(-I_{2}-I_{3}\right)+U_{2} I_{2}+U_{3} I_{3} \\
& \quad=z_{1}\left(-I_{2}-I_{3}\right)^{2}+z_{2} I_{2}^{2}+z_{3} I_{3}^{2} \\
& S^{*}=-U_{1}^{*} I_{2}-U_{1}^{*} I_{3}+U_{2}^{*} I_{2}+U_{3}^{*} I_{3} .
\end{aligned}
$$

Equation (20) can be simplified as

$$
\begin{aligned}
I_{2}\left(U_{2}-U_{1}\right) & +I_{3}\left(U_{3}-U_{1}\right) \\
& =\left(z_{1}+z_{2}\right) I_{2}^{2}+\left(z_{1}+z_{3}\right) I_{3}^{2}+2 z_{1} I_{2} I_{3} .
\end{aligned}
$$

From (21), current $I_{2}$ can be expressed as

$$
I_{2}=\frac{S^{*}-I_{3}\left(U_{3}^{*}-U_{1}^{*}\right)}{U_{2}^{*}-U_{1}^{*}} .
$$


Finally, by substituting (23) into (22), the following equation is obtained:

$$
\begin{aligned}
\frac{S^{*}-}{I_{3}\left(U_{3}^{*}-U_{1}^{*}\right)} & U_{2}^{*}-U_{1}^{*} \\
= & \frac{S^{* 2}-2 S^{*} I_{3}\left(U_{3}^{*}-U_{1}^{*}\right)+I_{3}\left(U_{3}\left(U_{3}^{*}-U_{1}^{*}\right)^{2}\right.}{\left(U_{2}^{*}-U_{1}^{*}\right)^{2}} \\
& \cdot\left(z_{1}+z_{2}\right)+\left(z_{1}+z_{2}\right) I_{3}^{2}+2 z_{1} \frac{S^{*}-I_{3}\left(U_{3}^{*}-U_{1}^{*}\right)}{U_{2}^{*}-U_{1}^{*}} .
\end{aligned}
$$

Equation (24) can be simplified as

$$
\begin{gathered}
{\left[\frac{2 z_{1}\left(U_{3}^{*}-U_{1}^{*}\right)}{U_{2}^{*}-U_{1}^{*}}-\frac{\left(z_{1}+z_{2}\right)\left(U_{3}^{*}-U_{1}^{*}\right)^{2}}{\left(U_{2}^{*}-U_{1}^{*}\right)^{2}}-\left(z_{1}+z_{3}\right)\right] I_{3}^{2}} \\
+\left[\left(U_{3}-U_{1}\right)-\frac{\left(U_{3}^{*}-U_{1}^{*}\right)\left(U_{2}-U_{1}\right)}{U_{2}^{*}-U_{1}^{*}}\right. \\
\left.\quad-\frac{2 z_{1} S^{*}}{U_{2}^{*}-U_{1}^{*}}+\frac{2 S^{*}\left(z_{1}+z_{2}\right)\left(U_{3}^{*}-U_{1}^{*}\right)}{\left(U_{2}^{*}-U_{1}^{*}\right)^{2}}\right] I_{3} \\
+\frac{S^{*}\left(U_{2}-U_{1}\right)}{U_{2}^{*}-U_{1}^{*}}-\frac{\left(z_{1}+z_{2}\right) S^{* 2}}{\left(U_{2}^{*}-U_{1}^{*}\right)^{2}}=0
\end{gathered}
$$

Currents $I_{2}$ and $I_{1}$ can be obtained from (18) and (23). Equations (18), (23), and (25) represent the steady-state solution for input currents under both unbalanced input voltages and unbalanced input impedances. An analytical solution represented by (25) always exists unless all the coefficients of the quadratic equations are equal to zero.

By setting the value for complex power $S=P+j Q$ in (23) and (25), the input power factor under unbalanced operating conditions can be varied

$$
p f=\frac{P}{\sqrt{P^{2}+Q^{2}}}
$$

where $P$ and $Q$ are input active and reactive power. For the unity power factor operation, the input reactive power $Q$ should be set to zero in (23) and (25).

\section{B. Critical Evaluation}

The analytical solution that has been obtained is general. In particular, the PWM boost-type rectifier can operate with unity power factor and still maintain dc voltage at the output. The only constraint that exists, as far as the level of imbalance is concerned, is governed by constraints of the operation of the PWM bridge itself.

The proposed generalized method for input-output harmonic elimination is valid if and only if $U_{i}, z_{i} \neq 0$, where $i=1,2,3$. In other words, the solution exists for all levels of imbalance in the input voltages and impedances, except for cases where both voltage and impedance in the same phase are equal to zero. Therefore, the maximum level of input voltage unbalance with

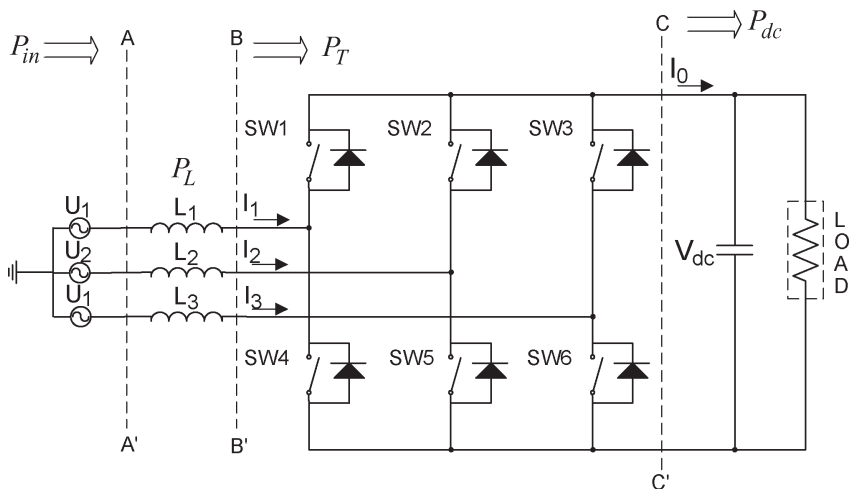

Fig. 2. Power flow of PWM boost-type rectifier under the proposed solution.

balanced input impedances, for which the proposed solution is still valid, is given as

$$
\begin{aligned}
& U_{1} \neq 0 \\
& U_{2}=U_{3}=0 \\
& z_{1}=z_{2}=z_{3} \neq 0 .
\end{aligned}
$$

Under unbalanced input voltages and unbalanced input impedances, the maximum level of imbalance, for which the proposed solution is still valid, is given as

$$
\begin{aligned}
U_{1} & \neq 0 \\
U_{2} & =U_{3}=0 \\
z_{1} & =0 \\
z_{2} & \neq z_{3} \neq 0 .
\end{aligned}
$$

From the above discussion, it follows that the three-phase PWM boost-type rectifier can operate from the single-phase supply as well (the special case of imbalance of the threephase system). This is an extremely important result, since it means that the three-phase PWM boost-type rectifier can operate from the center-tapped transformer as well and still maintain high-quality dc output voltage and ac input currents.

In this case, input voltages and impedances are given as

$$
\begin{aligned}
& \left|U_{1}\right|=\left|U_{3}\right| \\
& \operatorname{phase}\left(U_{1}\right)=0^{\circ} \\
& \operatorname{phase}\left(U_{3}\right)=-180^{\circ} \\
& U_{2}=0 \\
& z_{1}=z_{2}=z_{3} \neq 0 .
\end{aligned}
$$

\section{Physical Meaning of the Proposed Solution}

The harmonic elimination is achieved by nullifying the pulsation power $P_{T}$, as shown in Fig. 2, at the input terminals of the converter [1], [13]

$$
P_{\mathrm{in}}(t)=P_{L}(t)+P_{T}(t) .
$$

\section{Control Method}

Based on the analysis of the open-loop configuration presented above, a feedforward control method is proposed. Input voltages as well as input impedances have to be measured. 


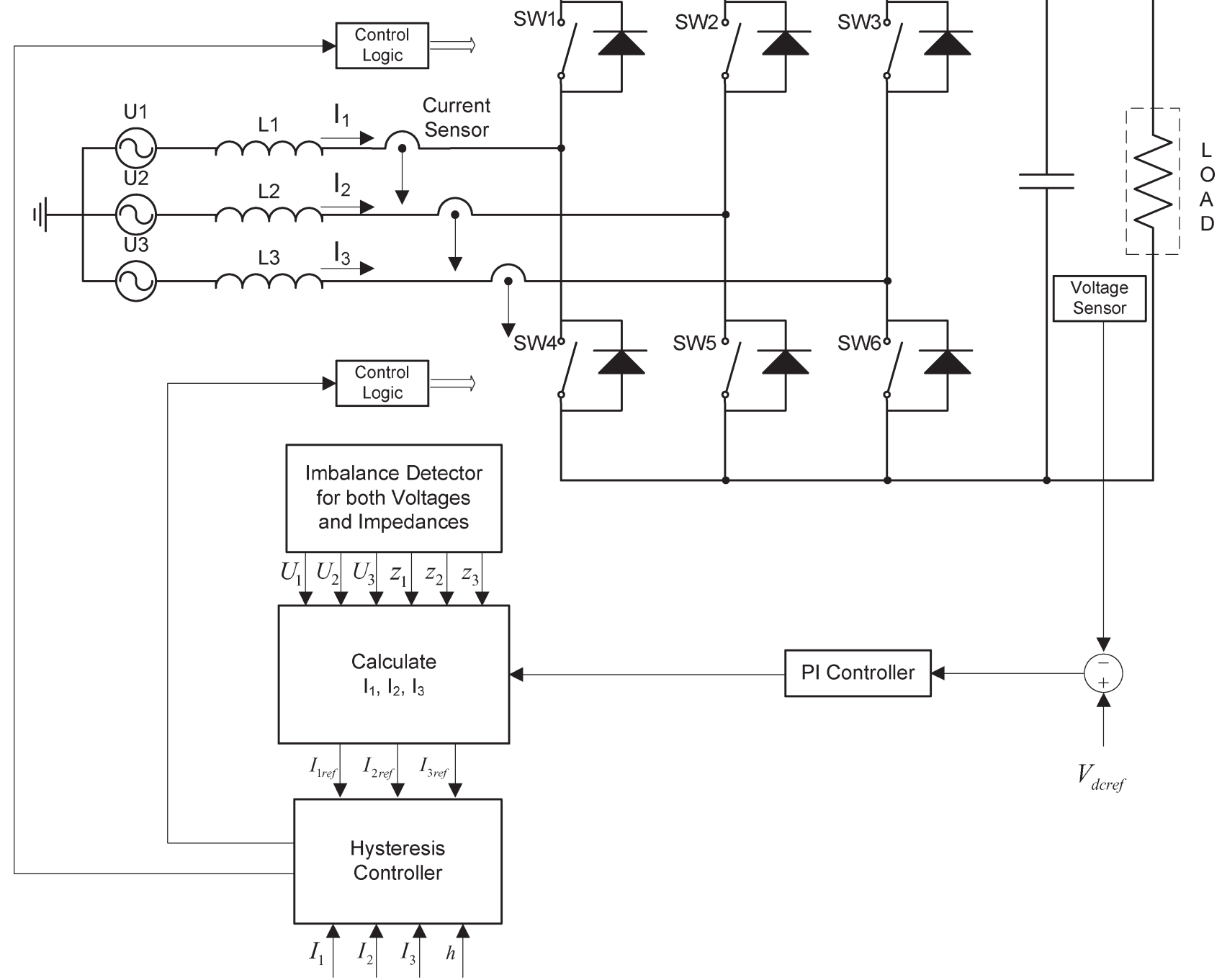

Fig. 3. Proposed closed-loop solution for input-output harmonic elimination under unbalanced input voltages and input impedances.

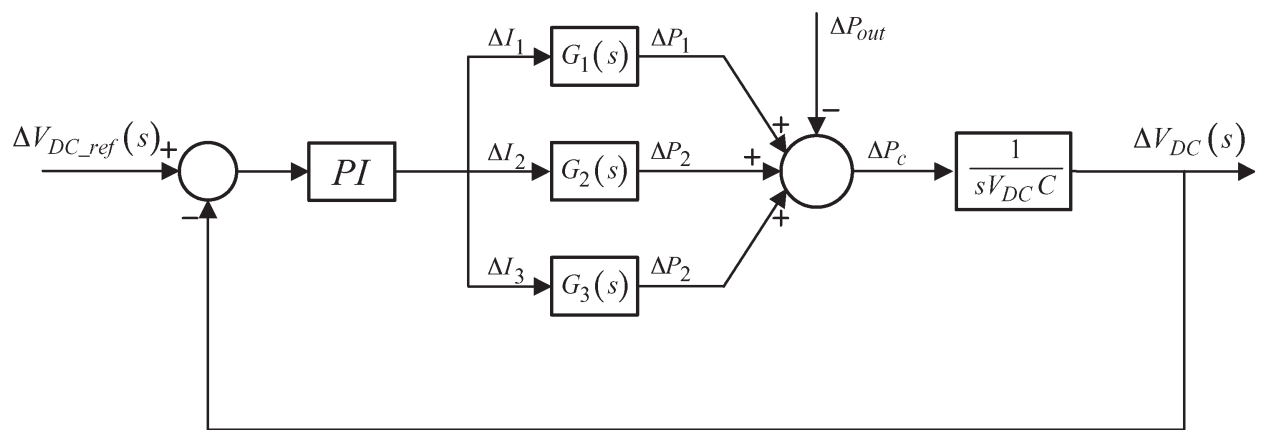

Fig. 4. Linearized model of the PWM rectifier under unbalanced operating conditions and the proposed controller.

Based on this information and a dc bus error, reference currents are calculated according to (18), (23), and (25) which become reference signals for the hysteresis controller [4]. Only one PI controller is utilized, which has been shown to be sufficient for good regulation. The proposed closed-loop control method is shown in more detail in Fig. 3.

\section{A. Stability of the Proposed Method}

The stability of the PWM boost-type rectifier under balanced operating conditions has been shown in [16]. Linearization about the equilibrium point has been used to derive the transfer function of the rectifier under unbalanced operating conditions and the proposed controller. The block diagram shown in Fig. 4 


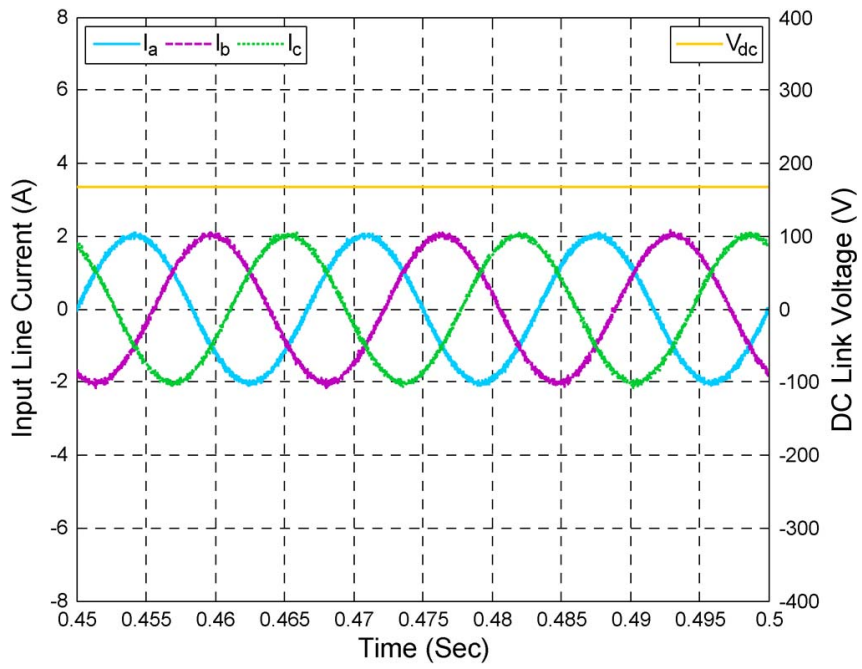

Fig. 5. Output dc voltage and input ac currents of CASE 1 (simulation results).

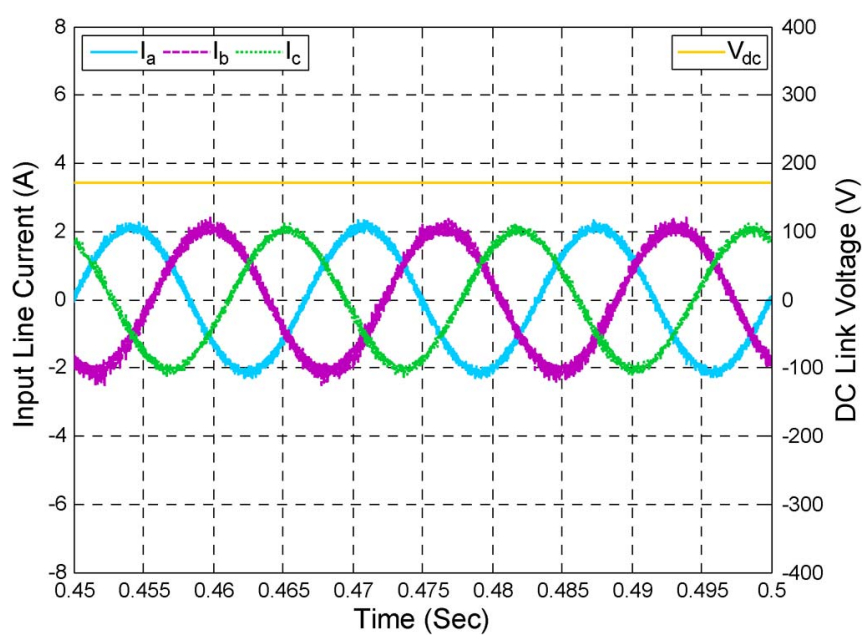

Fig. 6. Output de voltage and input ac currents of CASE 2 (simulation results).

represents a linearization of the system around the equilibrium operating point

$$
\begin{aligned}
& P I(s)=\frac{K_{I}+s K_{P}}{s} \\
& \left\{\begin{array}{l}
G_{1}(s)=U_{1} \cos \phi_{1}-s L_{1} I_{1}(s) \\
G_{2}(s)=U_{2} \cos \phi_{2}-s L_{2} I_{2}(s) \\
G_{3}(s)=U_{3} \cos \phi_{3}-s L_{3} I_{3}(s) .
\end{array}\right.
\end{aligned}
$$

According to stability criteria, the following relationships are obtained:

$$
\begin{aligned}
K_{P} & \leq \frac{C V_{\mathrm{dc}}}{L_{1} I_{1}+L_{2} I_{2}+L_{3} I_{3}} \\
K_{I} & \leq \frac{K_{P}\left(U_{1} \cos \phi_{1}+U_{2} \cos \phi_{2}+U_{3} \cos \phi_{3}\right)}{L_{1} I_{1}+L_{2} I_{2}+L_{3} I_{3}} .
\end{aligned}
$$

\section{Simulation Results}

The operation of the three-phase PWM boost-type rectifier under severe unbalanced operating conditions has been simu-

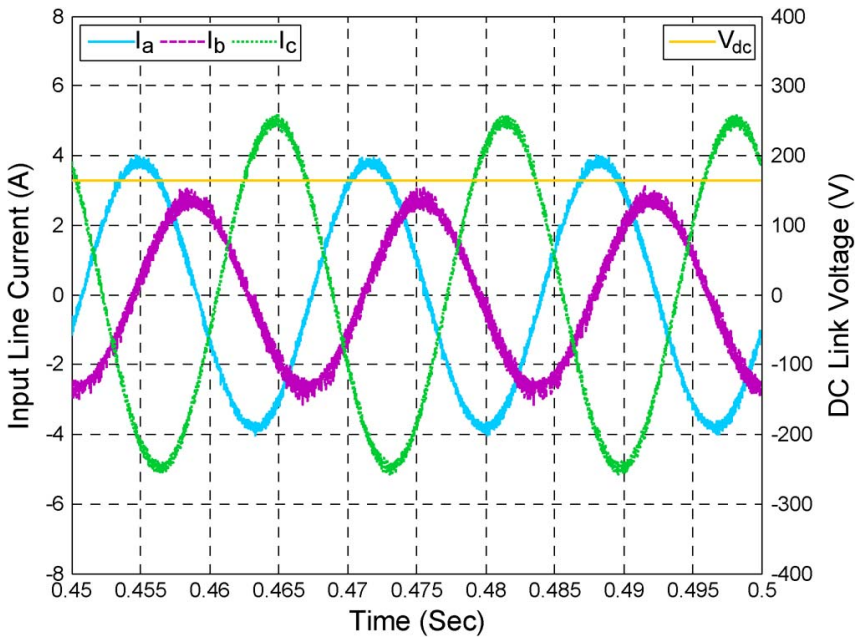

Fig. 7. Output dc voltage and input ac currents of CASE 3 (simulation results).

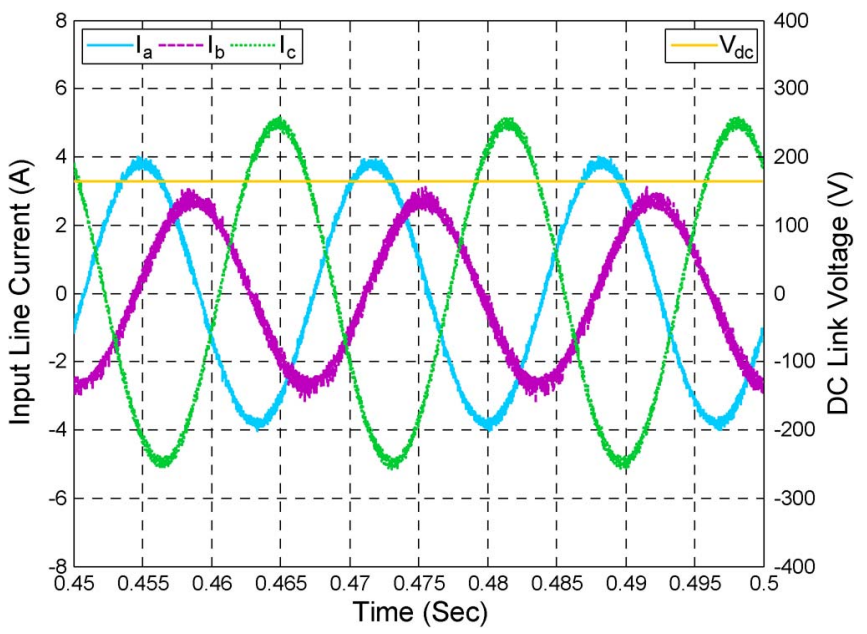

Fig. 8. Output dc voltage and input ac currents of CASE 4 (simulation results).

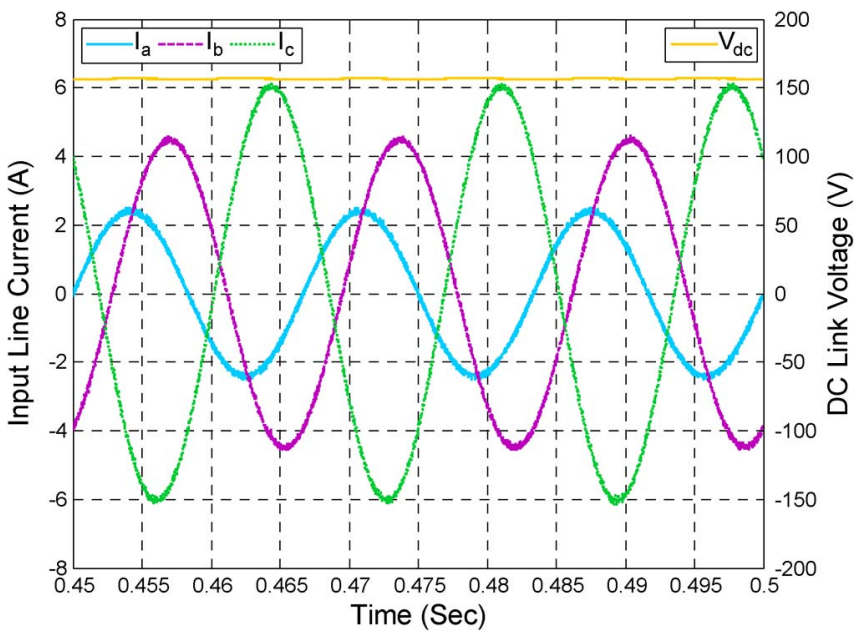

Fig. 9. Output dc voltage and input ac currents of CASE 5 (simulation results).

lated in MATLAB Simulink by using SimPowerSystems toolbox. Seven different cases have been selected for simulation. Simulation results verify the feasibility of the proposed control 


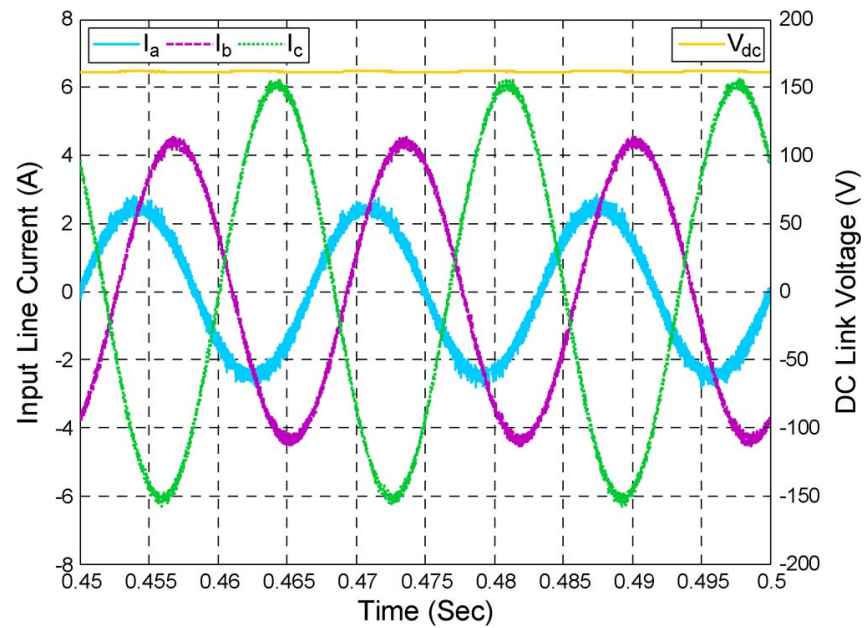

Fig. 10. Output de voltage and input ac currents of CASE 6 (simulation results).

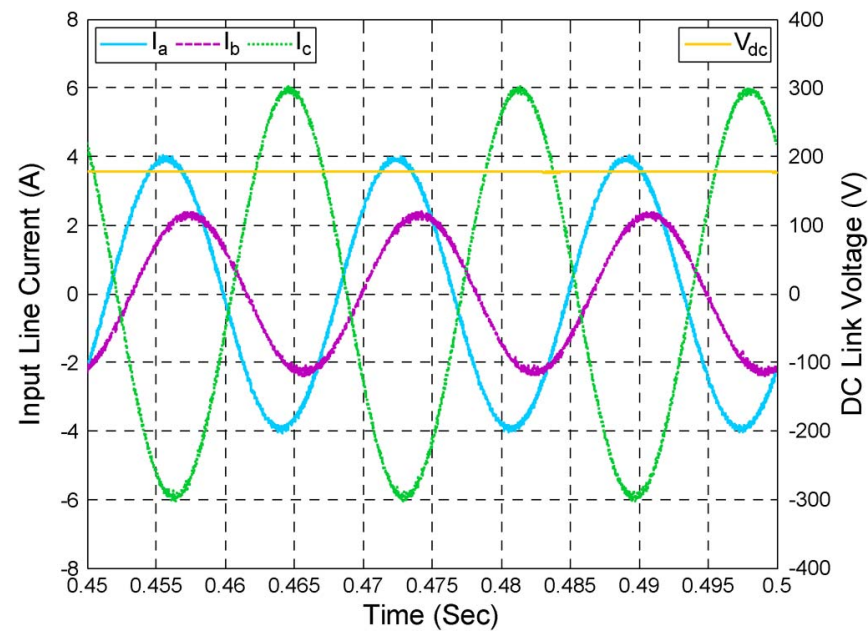

Fig. 11. Output dc voltage and input ac currents of CASE 7 (simulation results).

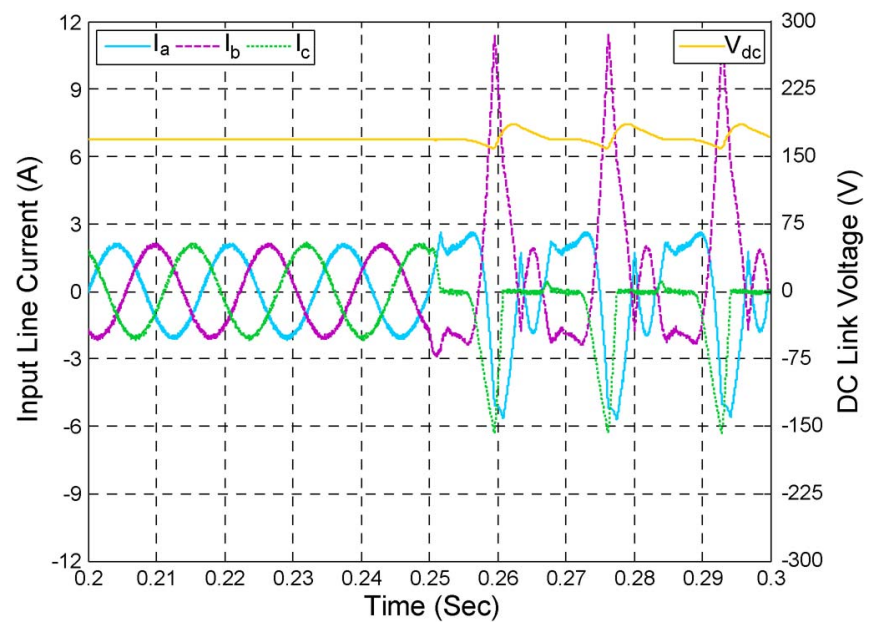

Fig. 12. Output de voltage and input ac currents with standard control method under fault condition: $U_{1}=60 \mathrm{~V}, U_{2}=60 \mathrm{~V}, U_{3}=0 \mathrm{~V}$ at $t=0.25 \mathrm{~s}$, $p f=1$.

method. The converter operates at unity power factor with a stable behavior in spite of level of imbalance of the input conditions. Insulated gate bipolar transistor (IGBT) and diode

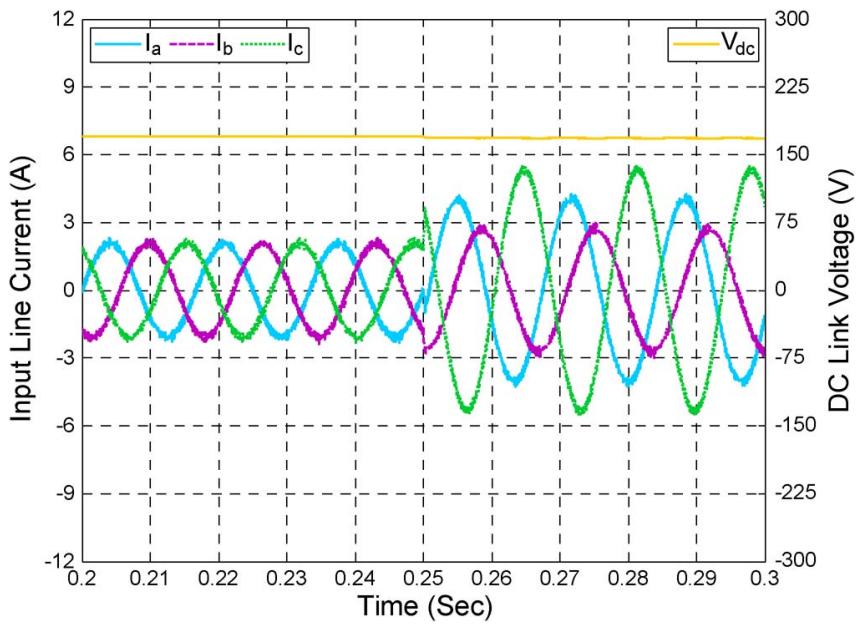

Fig. 13. Output dc voltage and input ac currents with proposed control method under fault condition: $U_{1}=60 \mathrm{~V}, U_{2}=60 \mathrm{~V}, U_{3}=0 \mathrm{~V}$ at $t=0.25 \mathrm{~s}$, $p f=1$.

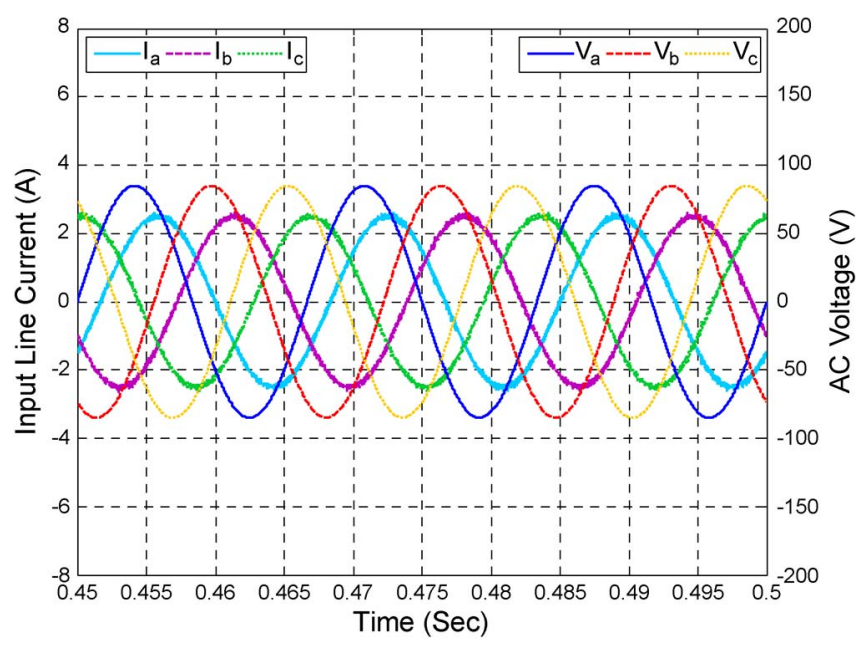

Fig. 14. Input voltages and currents under small level of imbalance in input voltages and $p f=0.8$ lagging.

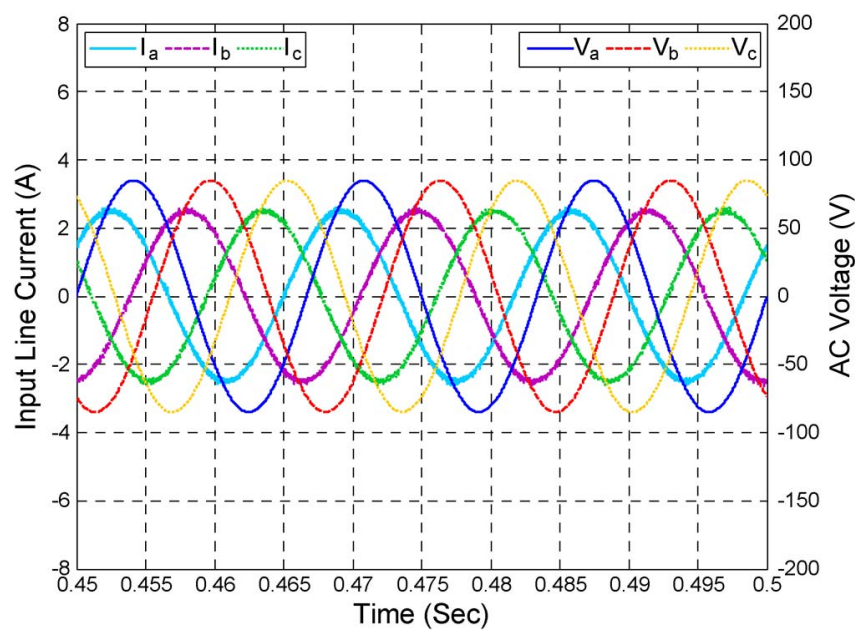

Fig. 15. Input voltages and currents under small level of imbalance in input voltages and $p f=0.8$ leading.

templates have been designed in simulation according to the datasheets of the PWM Lab-Volt IGBT module used in the experiment. 


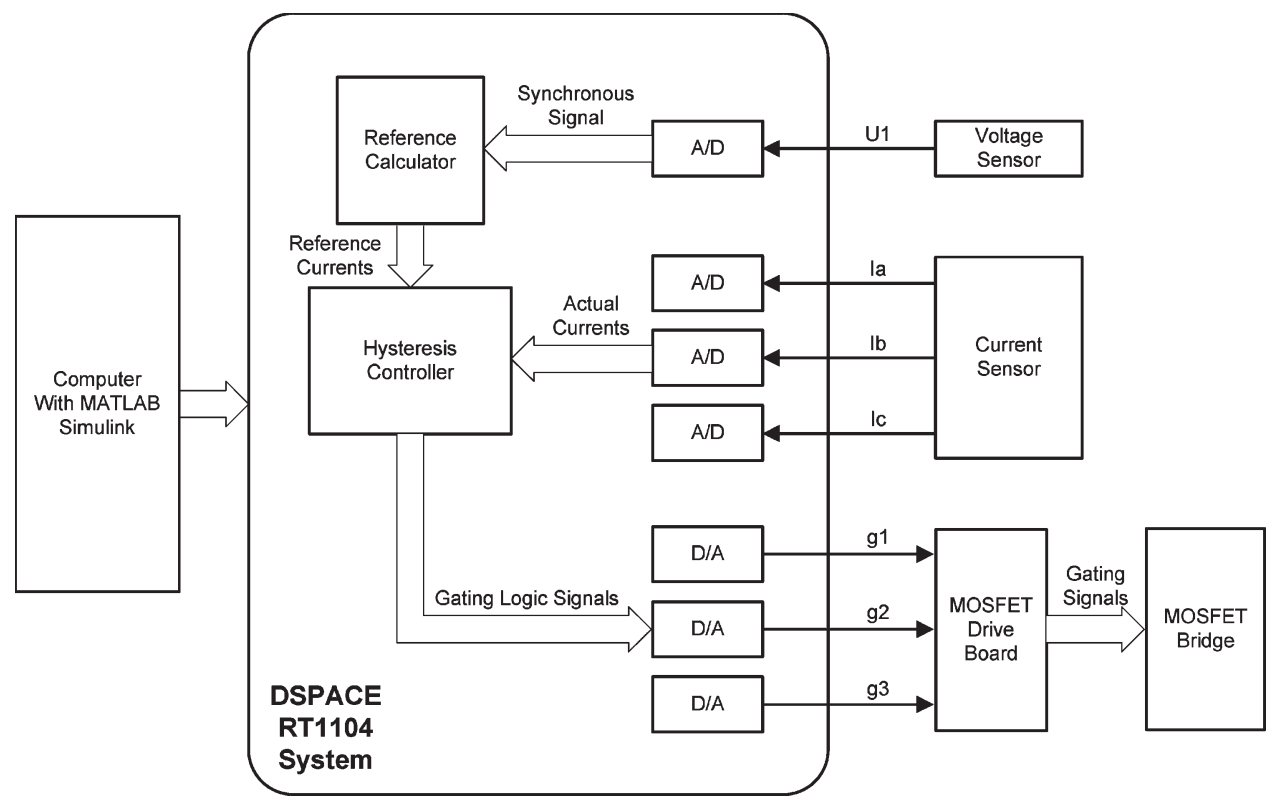

Fig. 16. Hardware configuration.

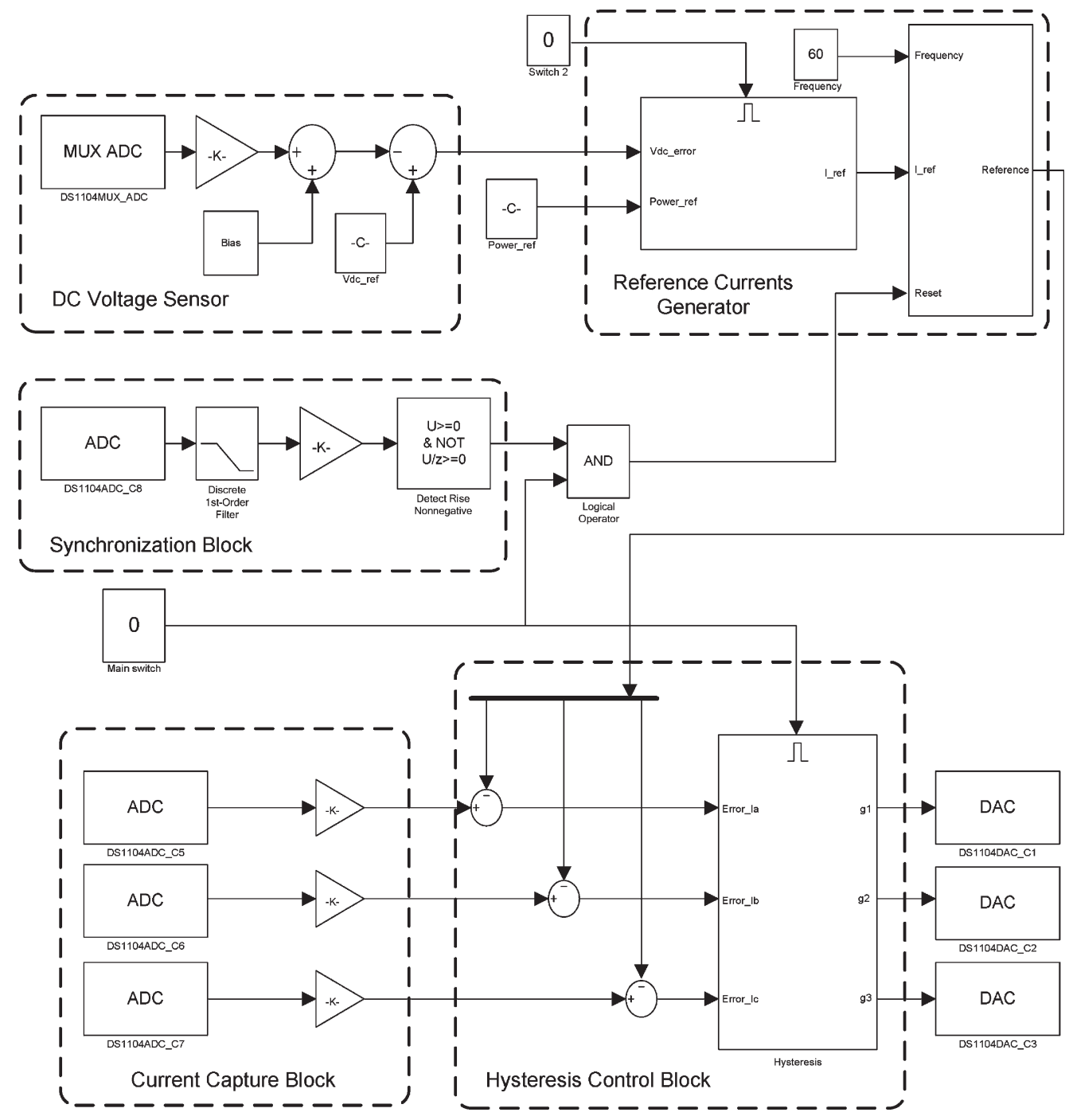

Fig. 17. Software configuration. 
Seven different cases, from balanced to extremely unbalanced operating conditions, have been selected to demonstrate the proposed control method, Figs. 5-11).

CASE 1 represents the operation of the PWM boost-type rectifier with the unity power factor under balanced operating conditions. No fault is present in this case.

In CASE 2, the PWM boost-type rectifier operates with the unity power factor under balanced input voltage conditions and unbalanced input impedances. One inductor was completely removed from the circuit.

In CASE 3, the rectifier operates at the unity power factor under unbalanced input voltages (single line-to-ground fault) and balanced input impedances.

In CASE 4, the rectifier operates with the unity power factor under unbalanced input voltages (single line-ground fault) and unbalanced impedances. One of three-phase impedances was eliminated from the circuit.

In CASE 5, the rectifier operates with the unity power factor under extremely unbalanced operating conditions (double lineground fault) and balanced impedances.

In CASE 6, the rectifier operates with the unity power factor under extremely unbalanced operating conditions (double lineground fault) and unbalanced input impedances. One of threephase impedances was eliminated from the circuit.

In CASE 7, the three-phase PWM boost-type rectifier operates with the unity power factor supplied from a center-tapped transformer.

In CASES 5-7, the load power has been reduced from 250 to $100 \mathrm{~W}$ in order not to exceed the current rating of the IGBTs in the Lab-Volt Module. In practical applications, the IGBTs should be rated for higher currents if the three-phase PWM boost-type rectifier were to be supplied from the center-tapped transformer. Under severe fault conditions, the load should be reduced if the currents exceed the ratings of the devices used in the PWM boost-type rectifier.

This is an extremely important result which allows the operation of the three-phase PWM boost-type rectifier in situation where the three-phase supply is not available.

Figs. 12 and 13 show the three phase currents and the output $\mathrm{dc}$ voltage under fault condition when the standard hysteresis controller [14] and the proposed algorithm is used. Figs. 14 and 15 show the adjustable power factor feature of the proposed algorithm.

\section{EXPERIMENTAL RESULTS}

The proposed control strategy has been implemented by using MATLAB Simulink and DSPACE RT1104 control system. The diagram of hardware configuration is shown in Fig. 16. Moreover, the software configuration is shown in Fig. 17. MATLAB Simulink program was used to design the control loop for the PWM boost-type rectifier. Several functional blocks shown in Fig. 17 of the Simulink model calculate input current references and generate switching logic signals. The DSPACE RT1104 controller is embedded in MATLAB Simulink using the Real-Time Workshop Toolbox, which converts the control logic and algorithm of the Simulink model into C code and downloads the code to DSPACE controller's

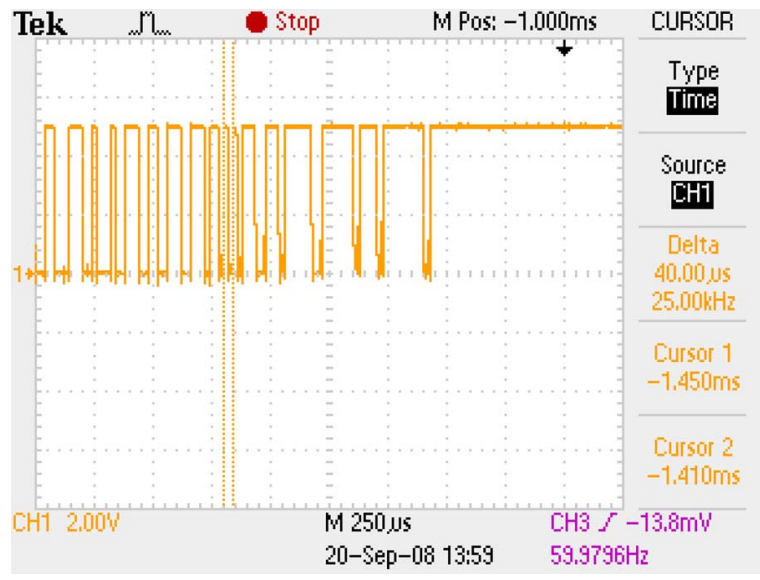

Fig. 18. Maximum switching frequency $f=25 \mathrm{kHz}$.

memory. Then, the DSPACE controller board can run the code in real time and achieve the functions designed in Simulink.

Three-phase IGBT module manufactured by Lab-Volt has been used in the power circuit. The dc link capacitor $C=$ $416 \mu \mathrm{F}$ has been used in the power circuit.

The powerful functions of MATLAB and Simulink have been used to calculate the current references given by (18), (23), and (25). It takes about $14 \mu$ s to obtain the solution to quadratic complex (25), (18), and (23). The switching frequency is variable. Moreover, for the set value of a sampling time $(20 \mu \mathrm{s})$ and the hysteresis band $(20 \mathrm{~mA})$, it does not exceed $25 \mathrm{kHz}$. It is shown in Fig. 18.

All seven cases represented in Table I have been experimentally verified. The waveforms of output dc voltage and input currents of seven cases are shown in Figs. 19-25.

Although in all seven CASES, the PWM boost-type rectifier operates under the unity power factor, CASE 7, the PWM boost-type rectifier supplied from the center-tapped transformer, was selected to demonstrate the unity power factor operation. Phase $A$ draws reactive power from the input, while phase $B$ supplies the same amount of reactive power so that the net input reactive power is equal to zero.

The unity power factor operation for CASE 7 is shown in Figs. 26-29. Even though the phase shift between the current and voltage in phases $A$ and $B$ exists, the overall input reactive power $Q$ is theoretically equal to zero.

The phase shift between phase $A$ voltage and current is shown in Fig. 26. Current in phase $A$ is lagging the voltage by $33.7^{\circ}$. The total reactive power supplying phase $A$ is given by

$$
Q_{1}=U_{1} I_{1} \sin \left(33.7^{\circ}\right)=93.9 \text { Var. }
$$

The phase shift between phase B voltage and current is shown in Fig. 28. Current is leading voltage by $112^{\circ}$. The total reactive power supplying phase $B$ is given by

$$
Q_{2}=U_{2} I_{2} \sin \left(-112^{\circ}\right)=-89.6 \text { Var. }
$$


TABLE I

SiMULATION CASES

\begin{tabular}{|c|c|c|c|c|}
\hline Case & Input Voltages & Input Impedances & $\begin{array}{c}\text { Power } \\
(\mathbf{W})\end{array}$ & $\begin{array}{c}\text { Load } \\
(\boldsymbol{\Omega})\end{array}$ \\
\hline 1 & $U_{1}=60 \angle 0^{\circ} \mathrm{V} \quad U_{2}=60 \angle-120^{\circ} \mathrm{V} \quad U_{3}=60 \angle 120^{\circ} \mathrm{V}$ & $L_{1}=L_{2}=L_{3}=10 \mathrm{mH}$ & 250 \\
\hline 2 & $U_{1}=60 \angle 0^{\circ} \mathrm{V} \quad U_{2}=60 \angle-120^{\circ} \mathrm{V} \quad U_{3}=60 \angle 120^{\circ} \mathrm{V}$ & $L_{1}=L_{3}=10 \mathrm{mH} \quad L_{2}=0$ & 250 & 114 \\
\hline 3 & $U_{1}=60 \angle 0^{\circ} \mathrm{V} \quad U_{2}=60 \angle-120^{\circ} \mathrm{V} \quad U_{3}=0$ & $L_{1}=L_{2}=L_{3}=10 \mathrm{mH}$ & 250 & 250 \\
\hline 4 & $U_{1}=60 \angle 0^{\circ} \mathrm{V} \quad U_{2}=60 \angle-120^{\circ} \mathrm{V} \quad U_{3}=0$ & $L_{1}=L_{3}=10 \mathrm{mH} \quad L_{2}=0$ & 114 \\
\hline 5 & $U_{1}=60 \angle 0^{\circ} \mathrm{V} \quad U_{2}=0 \quad U_{3}=0$ & $L_{1}=L_{2}=L_{3}=10 \mathrm{mH}$ & 100 & 342 \\
\hline 6 & $U_{1}=60 \angle 0^{\circ} \mathrm{V} \quad U_{2}=0 \quad U_{3}=0$ & $L_{1}=0 \quad L_{2}=L_{3}=10 \mathrm{mH}$ & 100 & 342 \\
\hline 7 & $U_{1}=60 \angle 0^{\circ} \mathrm{V} \quad U_{2}=60 \angle-180^{\circ} \mathrm{V} \quad U_{3}=0$ & $L_{1}=L_{2}=L_{3}=10 \mathrm{mH}$ & 100 & 400 \\
\hline
\end{tabular}

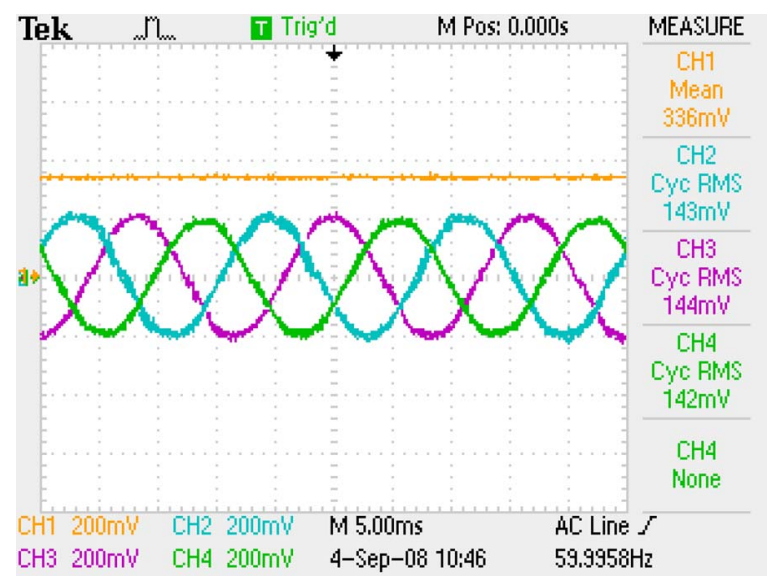

Fig. 19. Output dc voltage and input ac currents of CASE 1. Current probe$100 \mathrm{mv} / \mathrm{A}$. Voltage probe $-2 \mathrm{mV} / \mathrm{V}$.

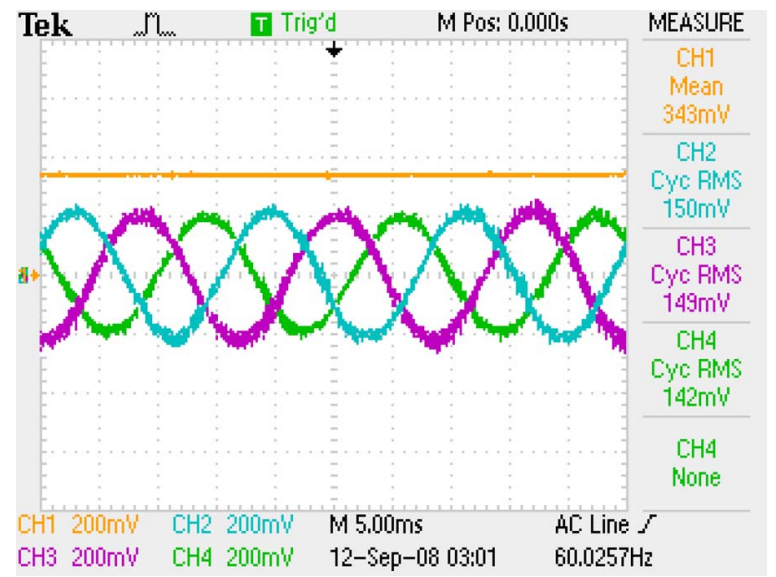

Fig. 20. Output dc voltage and input ac currents of CASE 2. Current probe$100 \mathrm{mv} / \mathrm{A}$. Voltage probe $-2 \mathrm{mV} / \mathrm{V}$.

The total input reactive power is given by

$$
\begin{aligned}
& Q=Q_{1}+Q_{2}=4.3 \mathrm{Var} \\
& P=P_{1}+P_{2}=104.6 \mathrm{~W} .
\end{aligned}
$$

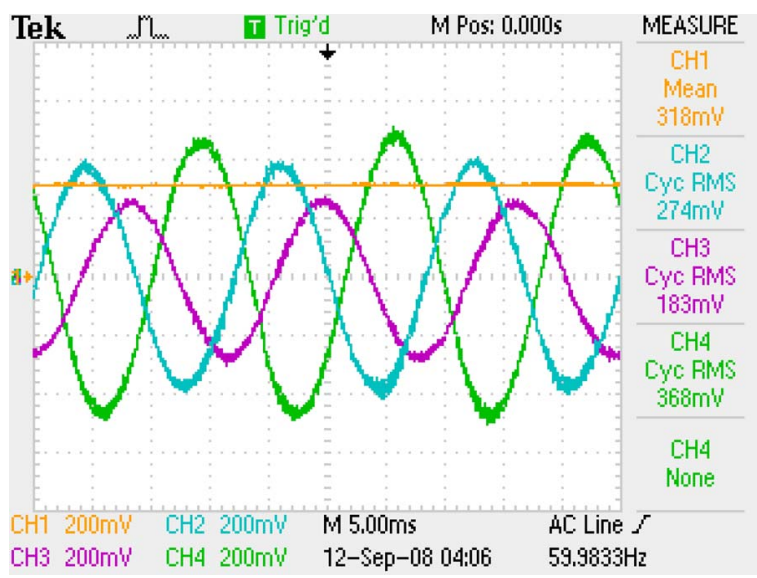

Fig. 21. Output dc voltage and input ac currents of CASE 3. Current probe$100 \mathrm{mv} / \mathrm{A}$. Voltage probe-2 $\mathrm{mV} / \mathrm{V}$.

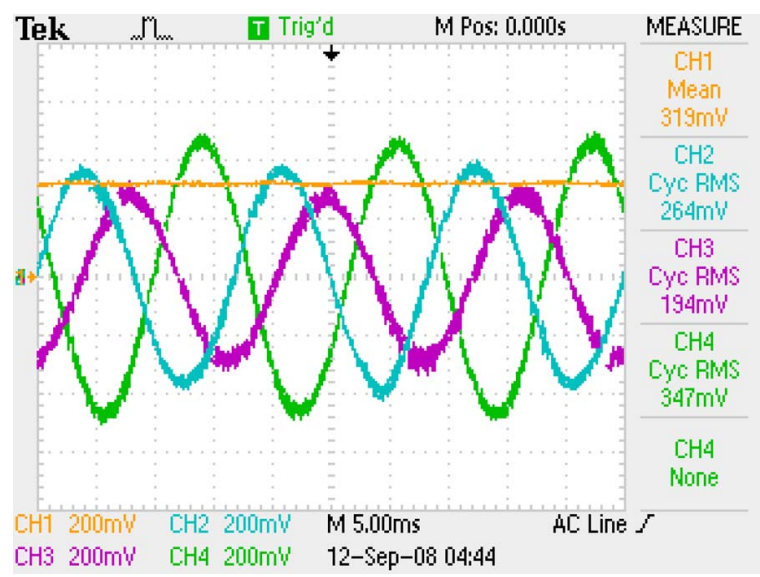

Fig. 22. Output dc voltage and input ac currents of CASE 4. Current probe$100 \mathrm{mv} / \mathrm{A}$. Voltage probe- $2 \mathrm{mV} / \mathrm{V}$.

The input power factor is then given by

$$
p f=\frac{P}{P^{2}+Q^{2}}=0.9992 .
$$

Table II shows the experimental results of the total harmonic distortion (THD) obtained in all seven cases. 


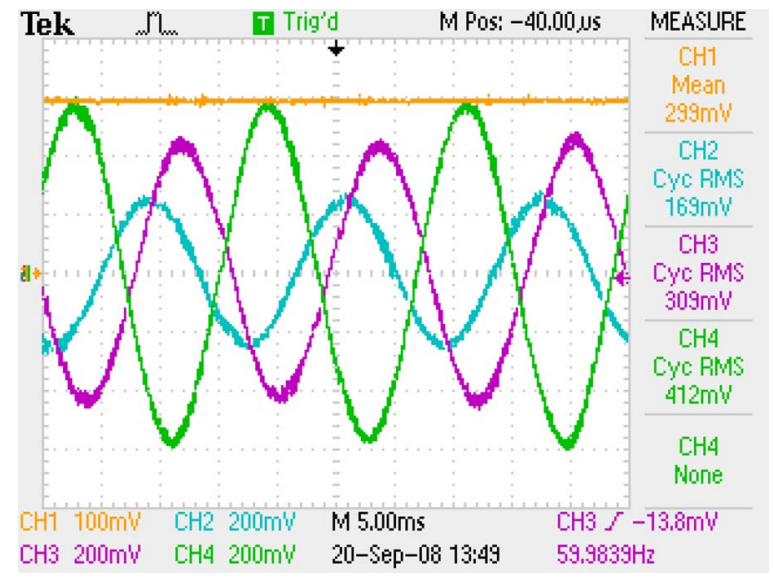

Fig. 23. Output dc voltage and input ac currents of CASE 5. Current probe$100 \mathrm{mv} / \mathrm{A}$. Voltage probe $-2 \mathrm{mV} / \mathrm{V}$.

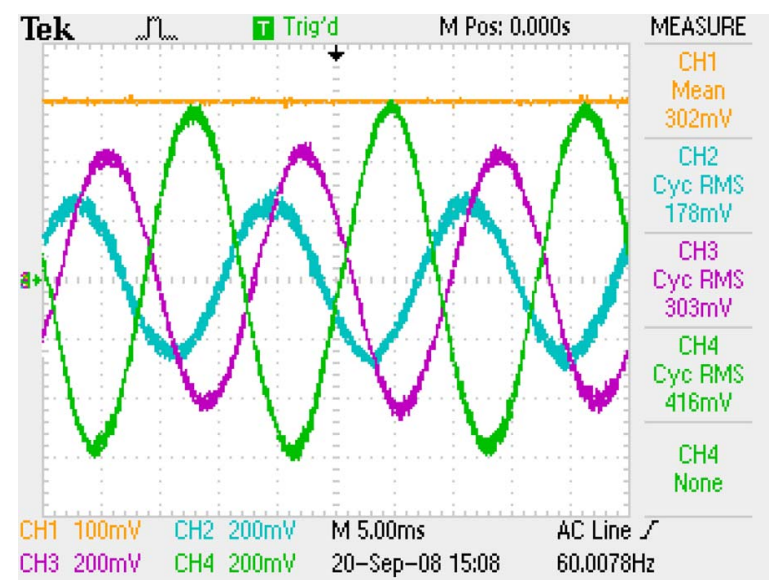

Fig. 24. Output de voltage and input ac currents of CASE 6. Current probe$100 \mathrm{mv} / \mathrm{A}$. Voltage probe $-2 \mathrm{mV} / \mathrm{V}$.

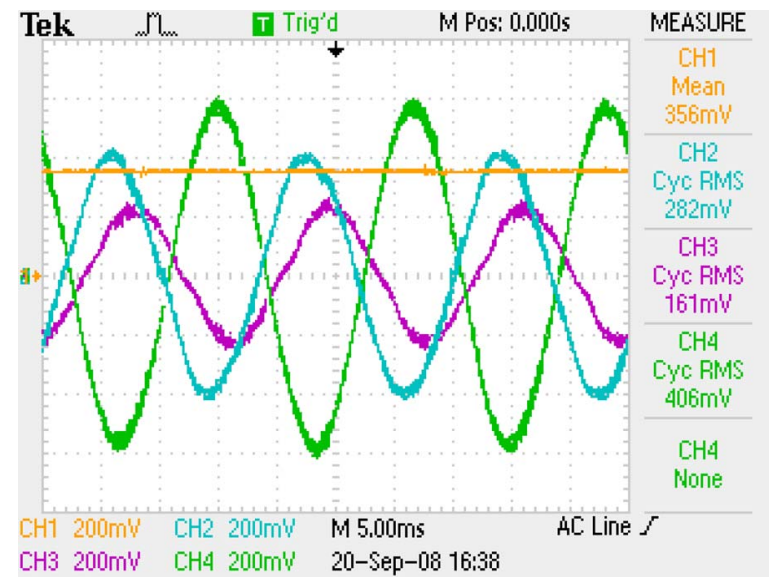

Fig. 25. Output dc voltage and input ac currents of CASE 7. Current probe$100 \mathrm{mv} / \mathrm{A}$. Voltage probe $-2 \mathrm{mV} / \mathrm{V}$.

\section{CONCLUSION}

This paper has proposed a new control method for input output harmonic elimination of the PWM boost-type rectifier under unbalanced input voltages and unbalanced input impedances.

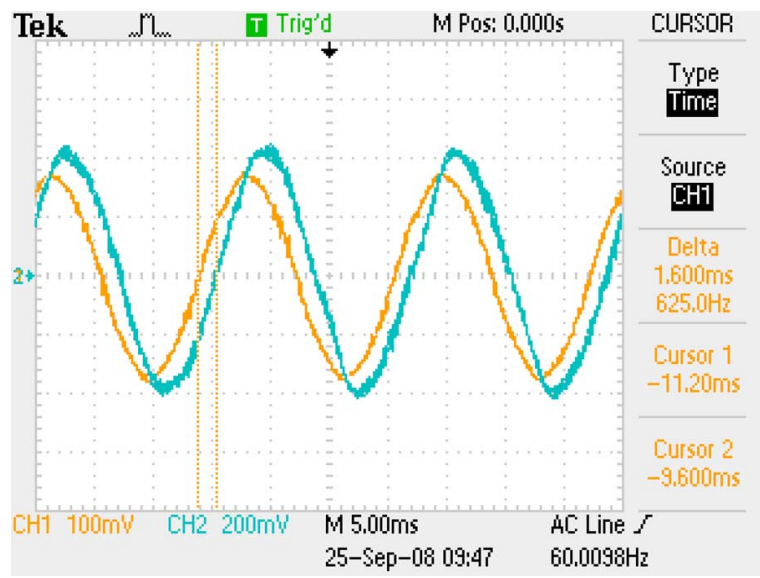

Fig. 26. Phase shift between voltage and current in phase A (CASE 7).

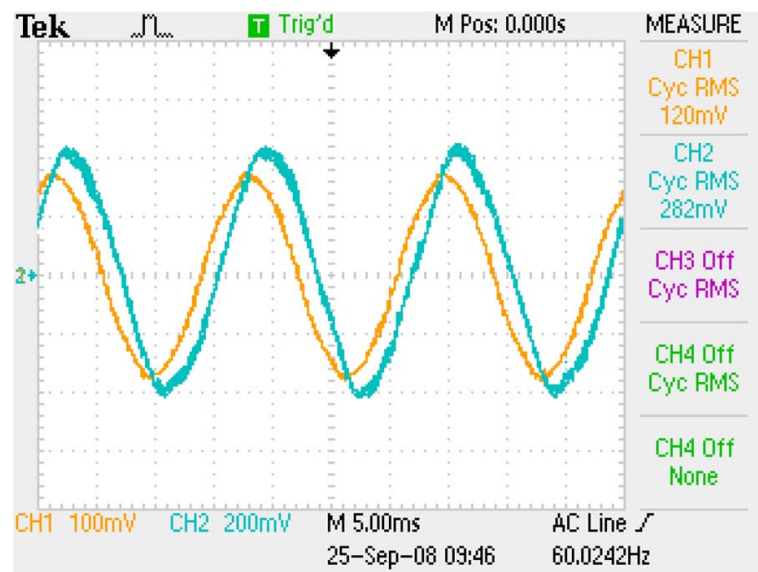

Fig. 27. Phase A current and voltage of CASE 7.

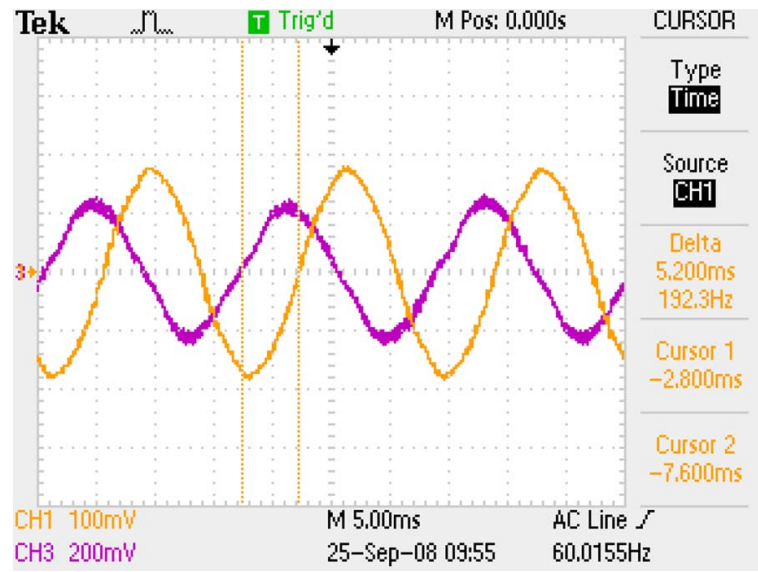

Fig. 28. Phase shift between voltage and current in phase B (CASE 7).

The theoretical approach for complete input-output harmonic operation of the PWM boost-type rectifier with adjustable power factor was presented. The range of imbalance in input voltages and input impedances was analyzed in detail. Based on the analyses in the open-loop configuration, the closedloop solution was proposed. An important result that follows is the possible operation of the three-phase PWM boost-type 


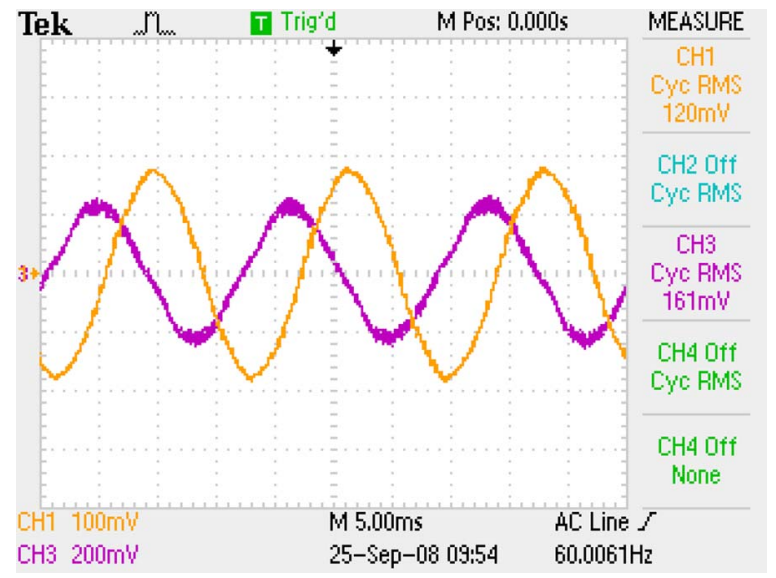

Fig. 29. Phase B current and voltage of CASE 7.

TABLE II

THD OF INPUT LINE CURRENTS (EXPERIMENTAL RESUlTS)

\begin{tabular}{|c|c|c|c|}
\hline \multirow{2}{*}{ CASE } & \multicolumn{3}{|c|}{ THD of Input Line Currents } \\
\cline { 2 - 4 } & Phase A & Phase B & Phase C \\
\hline $\mathbf{1}$ & $1.6 \%$ & $2.1 \%$ & $2.6 \%$ \\
\hline $\mathbf{2}$ & $2.4 \%$ & $1.9 \%$ & $2.0 \%$ \\
\hline $\mathbf{3}$ & $1.3 \%$ & $1.6 \%$ & $1.8 \%$ \\
\hline $\mathbf{4}$ & $1.5 \%$ & $1.5 \%$ & $1.3 \%$ \\
\hline $\mathbf{5}$ & $1.5 \%$ & $1.4 \%$ & $1.2 \%$ \\
\hline $\mathbf{6}$ & $1.6 \%$ & $1.5 \%$ & $1.3 \%$ \\
\hline $\mathbf{7}$ & $2.1 \%$ & $3.3 \%$ & $0.9 \%$ \\
\hline
\end{tabular}

rectifier from the single-phase supply-being the special case of imbalance in input voltages. Simulation and experimental results are in excellent agreement.

\section{REFERENCES}

[1] A. V. Stankovic and T. A. Lipo, "A novel control method for input output harmonic elimination of the PWM boost type rectifier under unbalanced operating conditions," IEEE Trans. Power Electron., vol. 16, no. 5, pp. 603-611, Sep. 2001.

[2] L. Moran, P. D. Ziogas, and G. Joos, "Design aspects of synchronous PWM rectifier-inverter system under unbalanced input voltage conditions," IEEE Trans. Ind. Appl., vol. 28, no. 6, pp. 1286-1293, Nov./Dec. 1992.

[3] J. W. Wilson, "The forced-commutated inverter as a regenerative rectifier," IEEE Trans. Ind. Appl., vol. IA-14, no. 4, pp. 335-340, Jul./Aug. 1978.

[4] D. M. Brod and D. W. Novotny, "Current control of VSI-PWM inverters," IEEE Trans. Ind. Appl., vol. IA-21, no. 4, pp. 769-775, Nov./Dec. 1984.

[5] P. Rioual, H. Pouliquen, and J. P. Louis, "Regulation of a PWM rectifier in the unbalanced network state," in Proc. IEEE PESC, 1993, pp. 641-647.
[6] P. Enjeti and S. A. Choudhury, "A new control strategy to improve the performance of a PWM AC to DC converter under unbalanced operating conditions," in Proc. IEEE PESC, 1991, pp. 382-389.

[7] T. A. Lipo, "Recent progress and development of solid state AC motor drives," IEEE Trans. Power Electron., vol. 3, no. 2, pp. 105-117, Apr. 1988.

[8] A. V. Stankovic and T. A. Lipo, "A novel control method for input output harmonic elimination of the PWM boost type rectifier under unbalanced operating conditions," in Proc. IEEE APEC, 2000, p. 666.

[9] Y. Suh, V. Tijeras, and T. A. Lipo, "A control method in DQ synchronous frame for PWM boost type rectifier under generalized unbalanced operating conditions," in Proc. IEEE PESC, vol. 3, 2002, pp. 1425-1430.

[10] B. Yin, R. Oruganti, S. K. Panda, and A. K. S. Bhat, "An output-powercontrol strategy for a three-phase PWM rectifier under unbalanced supply conditions," IEEE Trans. Ind. Electron., vol. 55, no. 5, pp. 2140-2151, May 2008.

[11] Y. Suh and T. A. Lipo, "Control scheme in hybrid synchronous stationary frame for PWM AC/DC converter under generalized unbalanced operating conditions," IEEE Trans. Ind. Appl., vol. 42, no. 3, pp. 825-835, May/Jun. 2006

[12] O. Ojo and Z. Wu, "A new controller for three-phase boost rectifiers lacking balance in source voltages and impedances," in Proc. IEEE APEC, Mar. 2005, vol. 1, pp. 508-514

[13] A. V. Stankovic and T. A. Lipo, "A generalized control method for input-output harmonic elimination for the PWM boost rectifier under simultaneous unbalanced input voltages and input impedances," in Proc. IEEE PESC, vol. 3, Jun. 2001, pp. 1309-1314.

[14] J. W. Dixon and B. Ooi, "Indirect current control of a unity power factor sinusoidal current boost type three-phase rectifier," IEEE Trans. Ind. Electron., vol. 35, no. 4, pp. 508-515, Nov. 1988.

[15] A. Emadi, Handbook of Automotive Power Electronics and Motor Drives. Boca Raton, FL: CRC Press, 2005.

[16] M. H. Rashid, Power Electronics Handbook. New York: Academic, 2001. 